\title{
Population genetic structure of the neon damselfish (Pomacentrus coelestis) in the northwestern Pacific Ocean
}

\author{
Shang-Yin V. Liu $\cdot$ Tomoyuki Kokita $\cdot$ Chang-Feng Dai
}

Received: 18 May 2007 / Accepted: 25 March 2008 / Published online: 8 April 2008

(C) Springer-Verlag 2008

\begin{abstract}
The population genetic structure of the neon damselfish (Pomacentrus coelestis) in the northwestern Pacific Ocean was revealed by the hypervariable control region of the mitochondrial gene (343 bp). In total, 170 individuals were sampled from 8 localities distributed between Taiwan and Japan, and 71 haplotypes were obtained through sequence alignment. High haplotype diversity ( $h=0.956 \pm 0.008)$ with low nucleotide diversity ( $\pi=0.010 \pm 0.006)$ was observed, and the results of the mismatch distribution test suggested that a historical population expansion after a period of population bottleneck might have occurred among P. coelestis populations. Based on the results of the UPGMA tree and AMOVA $(\Phi c t=0.193, P<0.05)$ analyses, fish populations from eight localities could be divided into two groups: one includes populations from localities around mainland Japan, and the other includes those from Okinawa and southern Taiwan. A genetic break was found between populations from mainland Japan and Okinawa, and this break was congruent with the pattern of phenotypic variations documented in previous studies. This evidence supports the latitudinal variation of reproductive traits among $P$. coelestis
\end{abstract}

Communicated by K. Yin.

Electronic supplementary material The online version of this article (doi:10.1007/s00227-008-0967-2) contains supplementary material, which is available to authorized users.

\footnotetext{
S.-Y. V. Liu · C.-F. Dai $(\bowtie)$

Institute of Oceanography,

National Taiwan University, Taipei, Taiwan

e-mail: corallab@ntu.edu.tw

T. Kokita

Department of Marine Bioscience,

Fukui Prefectural University, Fukui, Japan
}

populations likely being genetically based. It is suggested that the changes in sea level and sea surface temperatures during past glaciations might have resulted in population bottlenecks in $P$. coelestis and the modern populations in the northern West Pacific are likely the results of recolonization after such events. The Kuroshio Current acts not only as a vehicle for larval transport along its pathway (between populations in southern Taiwan and Okinawa) but also as a barrier for larval dispersal across the Kuroshio axis (between populations in mainland Japan and Okinawa).

\section{Introduction}

Understanding the population genetic structure of reef fishes is crucial to revealing their biogeography, local adaptations, and interconnectivity among populations (Planes 2002; Palumbi 2003). Previous studies on the genetic structure of marine organisms indicated that species with high dispersal abilities have little genetic divergence over large geographic distances, and the high level of gene flow may counteract genetic divergence and ultimately speciation (Shaklee 1984; Doherty et al. 1995; Hellberg 1996). However, increasing evidence has shown that reef fishes exhibit high genetic divergence even though some have high dispersal capacities (Shulman and Bermingham 1995; Taylor and Hellberg 2003, 2005). This controversy between dispersal capacity and genetic divergence may have resulted from large variations in larval behavior, selection regimes, oceanographic patterns, and historical events (Palumbi 1996; Planes 2002).

Pomacentrus coelesis, known as the neon damselfish, is widely distributed in the Indo-Pacific region (Allen 1991), with particular abundance in reef habitats between Taiwan 
and Japan. The island chain between Japan and Taiwan is comprised of about 140 subtropical islands. Due to the complex geological history and hydrodynamic patterns in this region, the phylogeography of terrestrial animals and plants have been the focus of many studies (e.g., Ota 1998; Chiang and Schaal 2006). In contrast to terrestrial organisms, the phylogeographic pattern of marine organisms is not fully understood due to very few studies have been conducted (Ogoh and Ohmiya 2005; Kojima et al. 2006). Kokita $(2003,2004)$ studied the latitudinal variation of reproductive traits of $P$. coelestis populations in the Ryukyu Islands and mainland Japan, and showed that their clutch size and size-specific clutch weight increased with increasing latitude, while egg size and inter-spawning intervals decreased with increasing latitude. Countergradient variations have also been reported in physiological traits of fishes such as the growth rate of Gasterosteus aculeatus and Gadus morhhua (Wright et al. 2004; Salvanes et al. 2004), sexual coloration of Poecilia reticulata (Grether et al. 2005) and the body shape of G. morhhua (Marcil et al. 2006). Such variations of fitness-related life history traits are possibly shaped by environmental conditions and selective regimes (Mousseau and Fox 1998). However, the latitudinal variation of phenotypic traits may be confused with local adaptations due to environmental variations. To reveal the interplay of local adaptations, it is necessary to measure the gene flow and perform common-environment experiments (Conover et al. 2006). Kokita (2003) conducted common-environment experiments and suggested that such latitudinal variations in reproductive traits of $P$. coelestis were likely to be genetically based and might be a consequence of local adaptations. Herein, we used the mitochondrial control region to reveal the genetic structure of $P$. coelestis populations between Taiwan and Japan since the generally high rate of base substitution makes the control region a marker of choice for addressing intraspecific phylogenetic questions (Meyer 1994). In addition, the mtDNA gives a good record of population size variations because of its smaller effective population size. Fish samples collected from Taiwan and those collected from the same localities described in Kokita $(2003,2004)$ were analyzed in an attempt to discern any environmental and genetic effects on variations in reproductive traits.

\section{Materials and methods}

\section{Samples and DNA extraction}

Fish samples of $P$. coelestis were collected with barrier nets by scuba diving at eight localities along the Kuroshio pathway (Fig. 1). The sampling sites, from north to south, were Kominato in Chiba Prefecture (KN), Okinoshima Island in
Fukuoka Prefecture (OS), Funakoshi in Ehime Prefecture (FS), Bohnotsu in Kagoshima Prefecture (BS), Tanegashima Island in Kagoshima Prefecture (TN), Nakanoshima Island in Kagoshima Prefecture (NS), Sesoko Island in Okinawa Prefecture (SK) (all in Japan), and Tiaoshi (TS) in southern Taiwan. Sample sizes ranged from 15 to 29 individuals (Table 1), and standard lengths ranged $40-70 \mathrm{~mm}$. Sampling localities in Japan were exactly the same as those described in Kokita $(2003$, 2004) representing Kominato (KN), Bohnotsu (BS) and Sesoko (SK). The method for DNA extraction was modified from that described in Liu et al. (2005). The voucher specimens of $P$. coelestis were deposited in Institute of Oceanography, National Taiwan University in Taipei, Taiwan.

\section{PCR and sequence analysis}

The partial mitochondrial control region was amplified using the universal primers CR-A and CR-E published in Lee et al. (1995). Each 25- $\mu$ l reaction contained 10-50 ng of DNA, $10 \mathrm{mM}$ Tris- $\mathrm{HCl}$ (pH 8.3), $50 \mathrm{mM} \mathrm{KCl}, 1.5 \mathrm{mM}$ $\mathrm{MgCl}_{2}, 1$ unit of Taq DNA polymerase (MDbio, Taipei), $0.2 \mathrm{mM}$ dNTPs, and $0.3 \mathrm{mM}$ of each primer, and the mixture was amplified with a cycling profile of $2 \mathrm{~min}$ at $94^{\circ} \mathrm{C}$ for the first cycle, followed by 34 cycles at $95^{\circ} \mathrm{C}(30 \mathrm{~s})$, $50^{\circ} \mathrm{C}(30 \mathrm{~s})$, and $70^{\circ} \mathrm{C}(40 \mathrm{~s})$. The nucleotide sequences of the PCR products were determined using an ABI 377 automated sequencer. The sequences obtained in this study were submitted to GenBank under accession numbers EF420785-EF420855.

\section{Data analyses}

Sequences of $P$. coelestis were aligned using CLUSTAL W (Thompson et al. 1994), followed by manual editing using Sequencher 4.2 (Gene Code, Ann Arbor, MI, USA). Data were analyzed by Arlequin 3.0 (Schneider et al. 2000). Unique haplotypes were counted. The haplotype diversity $(h)$, nucleotide diversity $(\pi)$, and their standard errors were estimated. TCS 1.21 (Clement et al. 2001) which used a 95\% confidence limit for parsimony (Templeton et al. 1995) was used to estimate a network of relationships among haplotypes and to construct the nested structure of the haplotypes. The fixation indices $\left(\Phi_{\mathrm{st}}\right)$ and gene flow values $\left(N_{m}\right)$ were estimated, and the significance of the $F$ statistics for population comparisons was assessed using 1,000 permutations. In addition, a pairwise mismatch distribution, comprised of the pairwise differences between all haplotypes, was performed for the historical demographic test. The distribution is usually multimodal when the data fit a demographic equilibrium. In contrast, a unimodal distribution may indicate recent demographic expansion (Slatkin and Hudson 1991). Furthermore, the Tajima's $D$ (Fu and Li 


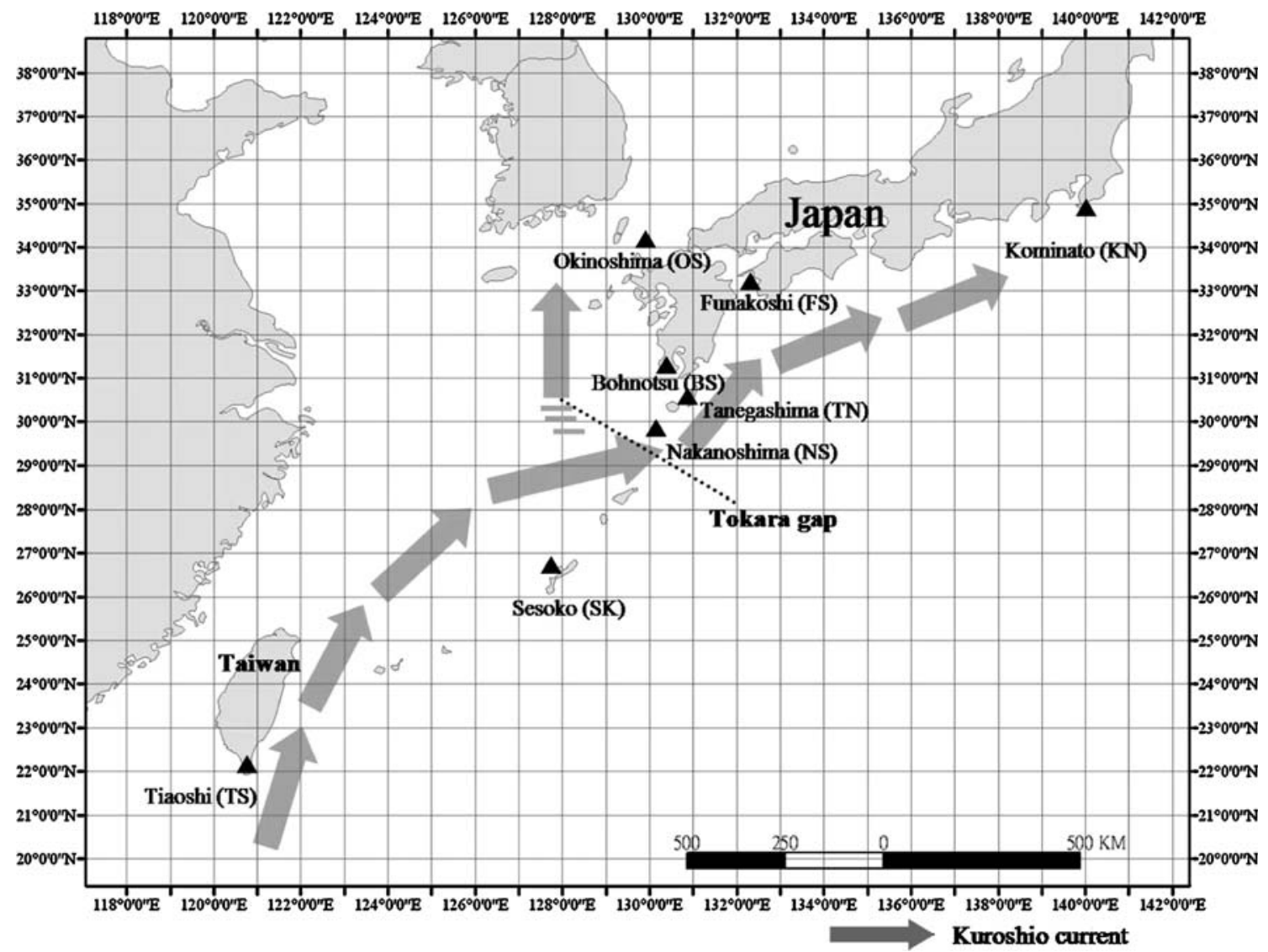

Fig. 1 Map showing the sampling localities of Pomacentrus coelestis populations in Taiwan and Japan. The solid arrows indicate the pathway of the Kuroshio Current and the dash line indicates the Tokara gap

Table 1 Collection localities, sample sizes $(n)$, number of haplotypes $\left(n_{h}\right)$, haplotype diversity $(h)$, and nucleotide diversity $(\pi)$ of Pomacentrus coelestis

\begin{tabular}{|c|c|c|c|c|c|c|}
\hline Abbreviation & Locality & Latitude & Longitude & $n$ & $n_{h}(h)$ & $\pi$ \\
\hline $\mathrm{KN}$ & Kominato, Chiba, Japan & $35.04^{\circ} \mathrm{N}$ & $140.07^{\circ} \mathrm{E}$ & 20 & $12(0.890 \pm 0.055)$ & $0.007 \pm 0.005$ \\
\hline OS & Okinoshima Island, Fukuoka, Japan & $34.09^{\circ} \mathrm{N}$ & $130.04^{\circ} \mathrm{E}$ & 29 & $18(0.934 \pm 0.034)$ & $0.010 \pm 0.006$ \\
\hline FS & Funakoshi, Ehime, Japan & $33.02^{\circ} \mathrm{N}$ & $132.16^{\circ} \mathrm{E}$ & 15 & $12(0.962 \pm 0.040)$ & $0.010 \pm 0.006$ \\
\hline BS & Bohnotsu, Kagoshima, Japan & $31.09^{\circ} \mathrm{N}$ & $131.09^{\circ} \mathrm{E}$ & 23 & $14(0.937 \pm 0.033)$ & $0.008 \pm 0.005$ \\
\hline $\mathrm{TN}$ & Tanegashima Island, Kagoshima, Japan & $30.43^{\circ} \mathrm{N}$ & $130.59^{\circ} \mathrm{E}$ & 26 & $14(0.938 \pm 0.024)$ & $0.010 \pm 0.006$ \\
\hline NS & Nakanoshima Island, Kagoshima, Japan & $29.30^{\circ} \mathrm{N}$ & $129.31^{\circ} \mathrm{E}$ & 22 & $16(0.961 \pm 0.028)$ & $0.012 \pm 0.007$ \\
\hline SK & Sesoko Island, Okinawa, Japan & $26.23^{\circ} \mathrm{N}$ & $127.31^{\circ} \mathrm{E}$ & 16 & $11(0.908 \pm 0.063)$ & $0.010 \pm 0.006$ \\
\hline $\mathrm{TS}$ & Tiaoshi, Taiwan & $21.57^{\circ} \mathrm{N}$ & $120.46^{\circ} \mathrm{E}$ & 19 & $12(0.871 \pm 0.073)$ & $0.008 \pm 0.005$ \\
\hline Total & & & & 170 & $71(0.956 \pm 0.008)$ & $0.010 \pm 0.006$ \\
\hline
\end{tabular}

1993) and Fu's $F_{s}$ (Fu 1996) tests were used to test for departures from mutation-drift equilibrium and to examine the historical demography of $P$. coelestis populations. The neutrality test was applied to examine deviations of Tajima's $D$ and Fu's $F_{s}$ values from a neutral state. In addition, the population expansion parameter, Tau $(\tau)$, can be used to estimate the time $(T)$ since the population expansion as $T=\tau / 2 \mu$, where $\mu$ is the mutation rate (Gaggiotti and Excoffier 2000).
AMOVA (analysis of molecular variance; Excoffier et al. 1992) was used to estimate $\Phi$ statistics which incorporate information on nucleotide differences between haplotypes. Hence the proportions of variations among regions $\left(\Phi_{\mathrm{ct}}\right)$, among populations within regions $\left(\Phi_{\mathrm{sc}}\right)$, and within populations $\left(\Phi_{\mathrm{st}}\right)$ were estimated. Random permutations of sequences among populations were evaluated to determine their significance. This hierarchical test can be used to reveal the degree of population subdivision (Schneider 
et al. 2000). A dendrogram representing the genetic relationships between sampling localities was constructed by UPGMA with Nei's genetic distance matrix generated in MEGA 3.1 (Kumar et al. 2004).

\section{Results}

After manual editing, 343 bp representing the mitochondrial control region was obtained from 170 specimens of $P$. coelestis. The haplotype composition of each population is shown in Electronic supplementary material S1. Fifty variable sites and 29 parsimoniously informative sites were found among 71 haplotypes. The nucleotide composition was $33.90 \% \mathrm{~A}, 33.25 \% \mathrm{~T}, 16.51 \% \mathrm{C}$, and $16.35 \% \mathrm{G}$. The ratio between transitions and transversions was 2.93:1. The nucleotide diversity $(\pi)$ ranged from $0.007 \pm 0.005$ to $0.012 \pm 0.007$, and haplotype diversity $(h)$ ranged from $0.871 \pm 0.073$ to $0.961 \pm 0.028$ among localities (Table 1 ).

\section{Patterns of historical demography}

The relationships between haplotypes were shown on a haplotype network tree (Fig. 2) with the "bush-like" structure on some dominate haplotypes indicating a relatively recent expansion. The mismatch distributions of all P. coelestis populations were unimodal, except that in SK (Fig. 3), and all populations fitted well with the expansion model suggesting a possible population expansion in the past. All Tajima's $D$ values were negative, but only those of TS and OS significantly deviated from a neutral state $(P<0.05)$ indicating the results of both selection and population expansion. In addition, Fu's $F_{s}$ values were all negative and deviated from a neutral state $(P<0.01)$, suggesting the effects of population growth or genetic hitchhiking. All evidences suggest that $P$. coelestis may have experienced a possible population-expansion event in the past.

The estimation of mutation rates of the $5^{\prime}$ portion of the mitochondrial control region in bony fish varies among species due to the paucity of fish fossils. In the damselfish, Chromis chromis, the mutation rate ranges from 8.2 to $9.3 \%$ per million years (Domingues et al. 2005). The $\tau$ values ranged from 1.005 to $4.461(2.850 \pm 1.101$, mean $\pm \mathrm{SD}$ ) (Table 2), and the time since population expansion of $P$. coelestis was about $27,000-70,000$ years before the present.

\section{Population genetic structure}

The pairwise $\Phi_{\mathrm{st}}$ values (Table 3) did not significantly differ $(P>0.05)$ among populations from mainland Japan $(\mathrm{KN}$, FS, BS, TN, and OS). Moreover, no significant difference was found between TS and SK populations or between SK

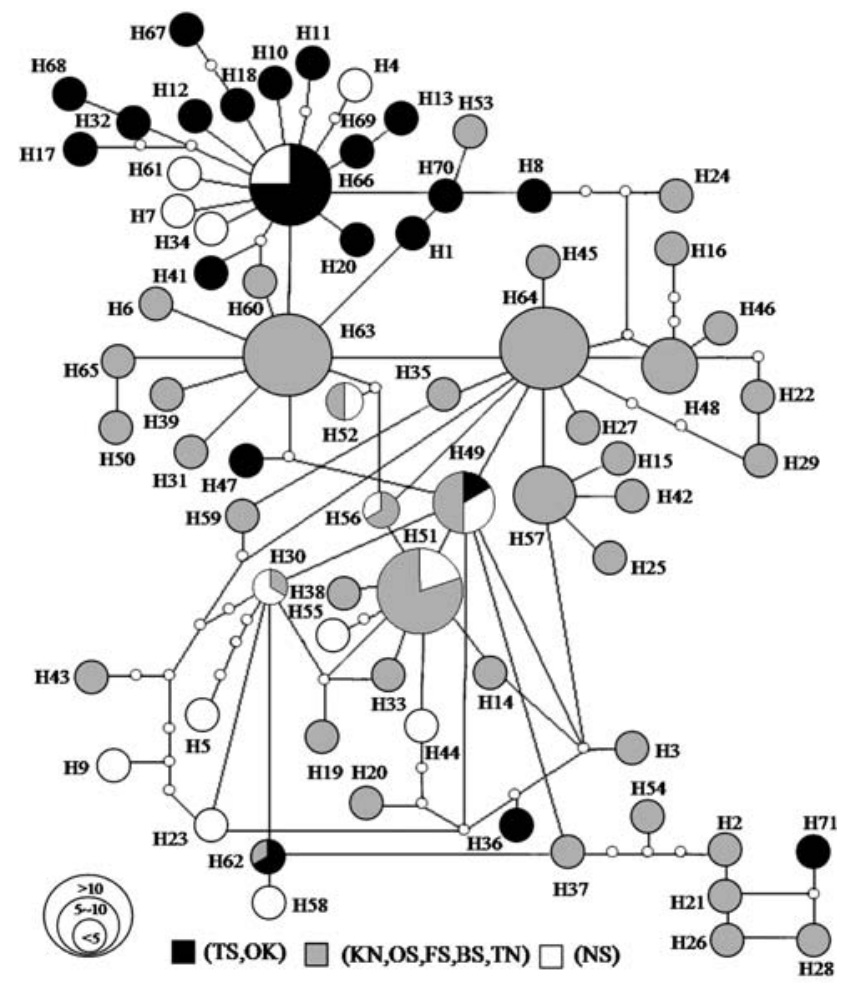

Fig. 2 The haplotype network of Pomacentrus coelestis. Black circles represent haplotypes from mainland Japan, gray circles represent haplotypes from Taiwan and Okinawa, and white circles represent haplotypes from Nakanoshima. Small hollow circles between haplotypes represent intermediate hypothesized haplotypes. Details of haplotype distribution are given in the Electronic supplementary material (S1)

and NS populations. In both cases, gene flow was not significantly lower than the average level between localities. However, $\Phi_{\mathrm{st}}$ values between populations from mainland Japan and TS, SK, and NS were high with significant differentiation $(P<0.01)$. Minor genetic differentiation was found between NS and populations from mainland Japan $(P<0.05)$. Moreover, the estimated gene flow per generation $\left(N_{m}\right)$ ranged from infinite to 1.096 . The infinite $N_{m}$ value indicates that extremely high gene flow has occurred between populations, while those lower than 11 are considered to be low gene flow between localities (Table 3).

The UPGMA tree showed that populations from the eight sampling sites were grouped into two major clusters (Fig. 4): one cluster contained populations from mainland Japan (KN, FS, BS, OS, and TN), and the other included populations from Okinawa (SK) and Taiwan (TS). This grouping corresponds to the haplotype distribution in the network tree (Fig. 2). Furthermore, a genetic break was found at the Tokara Gap according to the $\Phi_{\mathrm{st}}$ and AMOVA analyses (Fig. 1) that divided P. coelestis populations into two groups. 

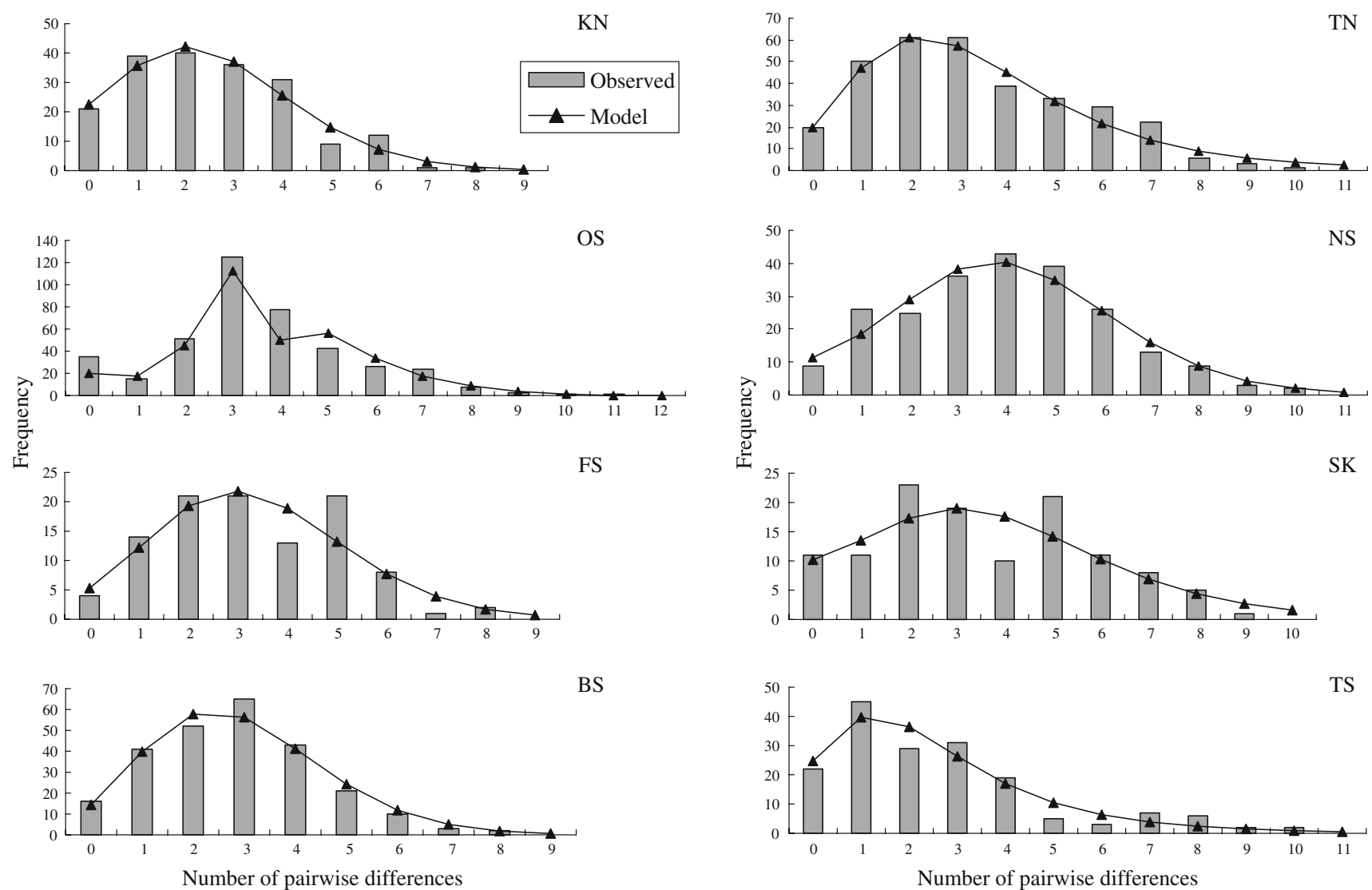

BS
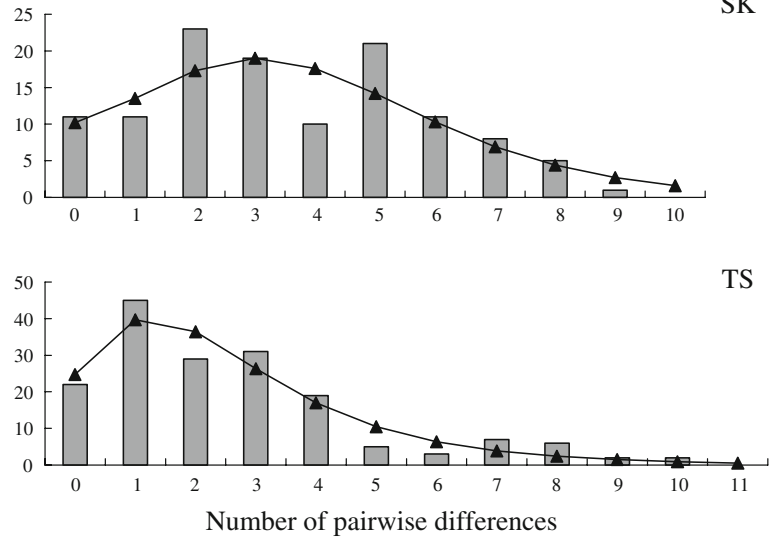

Fig. 3 Mismatch distributions of eight Pomacentrus coelestis populations. The curves represent the distributions fitted to the data under a model of population expansion

Table 2 Results of Tajima's $D$ and Fu's $F_{s}$ neutrality tests for Pomacentrus coelestis

\begin{tabular}{llll}
\hline & Tajima's $D$ & $F_{s}$ & $\tau$ \\
\hline KN & -1.302 & $-6.204^{* *}$ & 2.448 \\
OS & $-1.602^{*}$ & $-10.251^{* *}$ & 3.677 \\
FS & -1.428 & $-7.053^{* *}$ & 3.520 \\
BS & -1.061 & $-7.766^{* *}$ & 2.935 \\
TN & -1.459 & $-5.549^{* *}$ & 1.775 \\
NS & -1.089 & $-8.895^{* *}$ & 4.461 \\
SK & -1.499 & $-4.347^{*}$ & 3.028 \\
TS & $-1.820 *$ & $-6.349^{* *}$ & 1.005 \\
\hline
\end{tabular}

$\tau$ indicates the parameter of expansion. Abbreviations of localities are given in Table 1

$* P<0.05 ; * * P<0.01$

\section{Discussion}

The relationship between phenotypic and genetic variations

Significant genetic divergences were found between $P$. coelestis populations in $\mathrm{KN}$ and $\mathrm{SK}\left(\Phi_{\mathrm{st}}=0.158, P<0.01\right)$ as well as between the BS and SK populations $\left(\Phi_{\mathrm{st}}=0.151\right.$,
$P<0.01)$. Furthermore, there was infinite gene flow between the $\mathrm{KN}$ and BS populations $\left(\Phi_{\mathrm{st}}=-0.022\right)$. This pattern is congruent with the phenotypic variations found among different latitudinal locations (Kokita 2003, 2004) with the sampling sites KN, BS, and SK representing high, middle, and low latitudes, respectively. Kokita (2003) showed that females of $P$. coelestis from low latitude (SK) spawned larger eggs than female from high $(\mathrm{KN})$ and middle (BS) latitudes at every temperature treatment in the common-environment experiments. Furthermore, size-specific clutch size and weight were greater in females from high latitude (KN). Kokita (2004) further suggested that the close correspondence between latitudes and these maternal reproductive traits may be a consequence of local adaptation.

The potential for local adaptation is determined by the interplay between the selection differential and the level of gene flow among locations (Conover et al. 2006). However, the adaptive divergence cannot be maintained under the circumstance of high gene flow because it will homogenize genetic variation across habitats. In this study, the limited gene flow found between latitudinal populations may play a crucial role in maintaining the phenotypic variations. The genetic divergence of $P$. coelestis populations along the 
Table 3 Pairwise $\Phi_{s t}$ and $N_{m}$ values between Taiwanese and Japanese populations of Pomacentrus coelestis

\begin{tabular}{llllllrrr}
\hline & KN & OS & FS & BS & TN & NS & SK \\
\hline KN & - & $\infty$ & $\infty$ & $\infty$ & $\infty$ & 7.627 & 2.667 \\
OS & -0.026 & - & $\infty$ & $\infty$ & $\infty$ & 6.217 & 2.753 \\
FS & -0.020 & -0.020 & - & $\infty$ & $\infty$ & 10.131 & 4.254 \\
BS & -0.022 & -0.012 & -0.033 & - & $\infty$ & 6.520 & 1.260 \\
TN & -0.017 & -0.015 & -0.016 & -0.009 & - & 5.568 & 2.822 \\
NS & $0.062^{*}$ & $0.074 * *$ & $0.047^{*}$ & $0.071^{*}$ & $0.082^{* *}$ & - & 1.240 \\
SK & $0.158^{* *}$ & $0.154^{* *}$ & $0.105^{* *}$ & $0.151^{* *}$ & $0.160^{* *}$ & 0.037 & 1.207 \\
TS & $0.313^{* *}$ & $0.284^{* *}$ & $0.247^{* *}$ & $0.287^{* *}$ & $0.293^{* *}$ & $0.168^{* *}$ & - & 0.009 \\
\hline
\end{tabular}

$\Phi_{\text {st }}$ values are shown below the diagonal and $N_{m}$ values above the diagonal. Abbreviations of localities are given in Table $1 . \infty=$ infinite $* P<0.05 ; * * P<0.01$

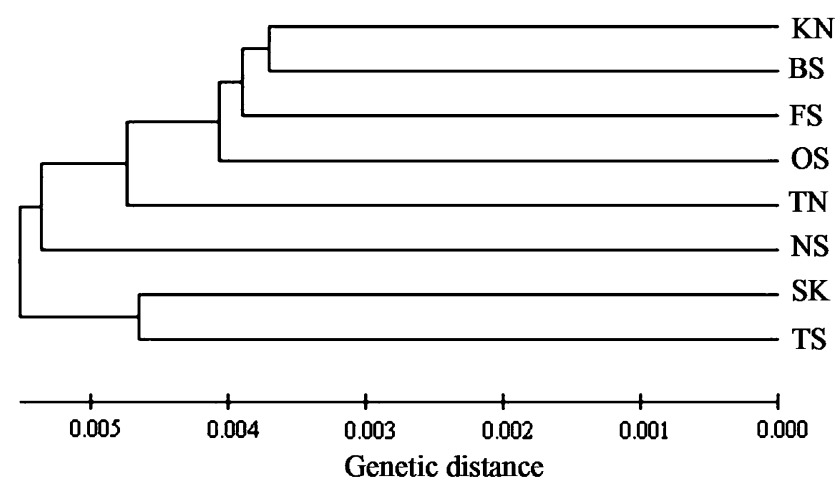

Fig. 4 UPGMA tree showing the genetic relationships among eight populations of Pomacentrus coelestis using Nei's (1978) genetic distance. Abbreviations of localities are given in Table 1

island chain between Japan and Taiwan may be related to the vicariance effect of ocean currents and self-recruitment of larvae. The Kuroshio Current with average speed of $1 \mathrm{~m} \mathrm{~s}^{-1}$ (Liang et al. 2003) may play a crucial role in segregating $P$. coelestis populations between Okinawa and mainland Japan since the pelagic larvae of $P$. coelestis, with limited mobility, are unlikely to penetrate the Kuroshio. During the last few years, many studies including circulation modeling (Cowen et al. 2006), trace element (Swearer et al. 1999), and tagging (Jones et al. 1999, 2005) experiments have suggested that reef fishes tend to stay where they settle. The prevalence of self-recruitment may result in limited gene flow among $P$. coelestis populations and further reinforce latitudinal variations of life history traits.

The consistency between population subdivision and phenotypic variation among local populations has been reported among different color morphs of reef fishes (Taylor and Hellberg 2003; Messmer et al. 2005). However, very few studies have shown the consistency between physiological traits and genetic variations. The results of this study suggest that variations in reproductive traits among $P$. coelestis populations are likely associated with genetic divergences.
Patterns of historical demographic and population structures

In contrast to the high haplotype diversity $(h=0.956 \pm$ $0.008)$, low nucleotide diversity $(\pi=0.010 \pm 0.006)$ was found in the $5^{\prime}$ portion of the mitochondrial control region among $P$. coelestis samples. This phenomenon was also found in several other reef fishes (e.g., Fauvelot et al. 2003; Chen et al. 2004). Grant and Bowen (1998) proposed four scenarios involving possible factors related to population dynamics to explain different combinations of small and large values of haplotype and nucleotide diversities. The first category includes species with low values of both $h$ and $\pi$ may represent a recent recolonization following periods of low effective population size within recent thousands or tens of thousands of years. The second category consists of populations with high $h$ and low $\pi$, which is the case of this study, can be attributed to rapid population expansion after a period of low effective population size. Many species of this category are believed to have originated in the Pliocene or early Pleistocene but their mtDNA genealogies coalesce on a more recent scale (Grant and Bowen 1998). The third category characterizes populations with low $h$ and high $\pi$ may result from secondary contact between isolated populations or by a strong bottleneck in a formerly large and stable population. The fourth category consists of species with high values of both $h$ and $\pi$ may be attributed to secondary contact between previously differentiated allopatric lineages or to a long evolutionary history in a large stable population.

Although little is known about the evolutionary history of $P$. coelestis, the high $h$ could be maintained within populations under several conditions such as a large population size, environmental heterogeneity, and life-history traits that favor rapid population expansion (Nei 1987). P. coelestis often occurs abundantly on temperate rocky reefs to coral reefs (Kokita 2003; Liu SYV unpublished data), and this phenomenon may account for the high level of genetic 
diversity (Avise 1998). Moreover, it was proposed that $P$. coelestis has an annual life cycle (Suzuki et al. 1985; Kokita unpublished data), and their minimum maturation size is $3.6 \mathrm{~cm}$ in standard length (Chen 1992). Females of $P$. coelestis often spawn multiple clutches, approximately five times per month, during the spawning season (Tanaka and Nitta 1997). Such life-history traits including early maturation, high reproductive investment, and large population size may contribute to rapid population growth and enhance the retention of new mutations that results in high $h$. The results of unimodal mismatch distribution and the deviation from neutrality test also suggest that $P$. coelestis populations have gone through rapid expansion after a period of low effective population size (Rogers and Hapending 1992; Grant and Bowen 1998). These possible factors may result in high $h$ and low $\pi$ observed among P. coelestis populations.

Tajima's $D$ and Fu's $F_{s}$ values of $P$. coelestis populations were all negative, and the bush-liked haplotype network was found in the haplotype tree. These findings are consistent with the high $h$ and low $\pi$, suggesting the occurrence of population expansion (Grant and Bowen 1998). Moreover, the results of goodness-of-fit test showed that our data fits well with the model of population expansion (Fig. 3). Similar phenomena have been reported in other studies demonstrating population structures after a possible historical expansion (Fauvelot et al. 2003; Chen et al. 2004). Sea-level changes during past glaciations were proposed as important factors in shaping the biogeography of damselfish (Nelson et al. 2000; Fauvelot et al. 2003). When sea surface temperature and sea level dropped during the last glaciations, such drastic environmental changes might have resulted in population bottlenecks among reef fish populations in shallow water habitats. Thus, the modern populations of $P$. coelestis in the northern West Pacific possibly represent the results of recolonization after such events.

Population structure of $P$. coelestis in the northern West Pacific

The population structure of marine species has long been assumed to be homogenous due to the long pelagic duration and lack of obvious geographical barriers in marine environments (Shaklee 1984). However, there was apparent restricted gene flow between $P$. coelestis populations of two groups, i.e., mainland Japan and Okinawa-Taiwan, along the Kuroshio pathway (Table 3). The UPGMA tree based on Nei's genetic distance also support the same genetic break. This grouping was further tested by hierarchical AMOVA analyses of three artificially divided groups representing different scenarios. First, the eight populations were assigned to four groups by considering isolation by the
Kuroshio Current and the land barrier of mainland Japan. Second, populations along the path of the Kuroshio were divided into three major groups. Third, the populations were assigned into two groups based on their genetic structure, i.e., the mainland Japan group and the Taiwan-Ryukyu group (Table 4). The results showed that most of the variances in all three groupings occurred at the within-population level. Significant genetic differentiations were found among/between groups of the second and third groupings $(P<0.05)$. The highest proportion of variance $(19.26 \%)$ was found between the two groups in the third scenario suggesting that this grouping represents the highest genetic differentiation among populations.

Similar patterns have been reported among reptiles, amphibians, plants, and fish (Ota 1998; Mukai et al. 2004, 2005; Chiang and Schaal 2006; Tseng et al. 2006), but most of those are terrestrial or freshwater organisms that are easily influenced by isolation among islands. The hypotheses that have been proposed to explain the phylogeography of terrestrial animals and plants between Taiwan and the Ryukyu Arc might not be appropriate for marine species such as $P$. coelestis. Herein, we propose a scenario to explain the population structure of $P$. coelestis based on historical events and hydrodynamic patterns. During the last glacial maximum (LGM), the Kuroshio Current did not enter the Okinawa Trough, but instead turned northeastward due to the appearance of a land bridge between Taiwan and the southern Ryukyus (Ujiié et al. 1991). Shifting of the Kuroshio pathway led to a decrease in sea surface temperature in coastal waters of East Asia, as suggested by CLIMAP Project Members (1981). During that period, coastal waters around mainland Japan might not be suitable habitats for $P$. coelestis due to the low water temperatures

Table 4 Hierarchical AMOVA within and among eight populations of Pomacentrus coelestis between Taiwan and Japan

\begin{tabular}{llll}
\hline Comparisons & Source of variance & $\begin{array}{l}\text { Percent total } \\
\text { variance }\end{array}$ & $\Phi$ Statistic \\
\hline (KN, FS, BS, & Among regions & 11.19 & 0.111 \\
TN, NS), & Among pop./ & 1.98 & $0.022^{*}$ \\
(TS), (OS), (SK) & within regions & & \\
& Within populations & 86.82 & $0.132^{*}$ \\
(KN, FS, BS, & Among regions & 18.06 & $0.181^{*}$ \\
TN, NS, OS), & Among pop./ & 1.30 & $0.016^{*}$ \\
(TS), (SK) & $\quad$ within regions \\
& Within populations & 80.63 & $0.194^{*}$ \\
(KN, FS, BS, & Among regions & 19.26 & $0.193^{*}$ \\
TN, NS, OS), & Among pop./ & 1.19 & $0.015^{*}$ \\
(TS, SK) & within regions & & \\
\hline
\end{tabular}

Abbreviations of localities are given in Table 1

$* P<0.05$ 
(about $6^{\circ} \mathrm{C}$ ), and the population might move to lower latitudes. Only after the glaciers receded and sea temperatures increased, did individuals of $P$. coelestis begin recolonizing the coastal areas of mainland Japan forming the present populations. When individuals of $P$. coelestis crossed the Takara Gap, they might rapidly spread along the eastern and western coastlines of Japan to fill in empty niches. When the present Kuroshio pathway was established in early Holocene, the current pattern might have constrained the gene flow between $P$. coelestis populations in mainland Japan and Okinawa.

The biogeographic pattern of $P$. coelestis is analogous with those of marine ostracods (Ogoh and Ohmiya 2005) and tideland snail Cerithidea cingulata (Kojima et al. 2006). Two deep straits, Tokara Gap and Kerama Gap, were suggested to be responsible for the phylogeographic patterns of amphibians and reptiles (Ota 1998). The present results indicated the Tokara Gap may affect the population structure of $P$. coelestis between mainland Japan and Okinawa. However, the Kerama Gap is unlikely acted as a barrier to $P$. coelestis since high gene flow persisted among populations between Okinawa and southern Taiwan populations $\left(\Phi_{\mathrm{st}}=0.009\right)$ which were separated by a distance of approximately $880 \mathrm{~km}$. Moreover, a shared haplotype (haplotype 66 in Electronic supplementary material $\mathrm{S} 1, n=12$ ) was found among individuals of southern Taiwan and Okinawa $(n=35)$ that represented about $1 / 3$ of all individuals. This phenomenon may represent a case of ancestral polymorphism or the consequence of a shared gene pool due to high gene flow between these two populations. In contrast, non-significant $\Phi_{\text {st }}$ value was found between $P$. coelestis populations in Nakanoshima (NS) and Okinawa (SK) which might be resulted from the fluctuations of Kuroshio axis across the Tokara Strait. When Kuroshio passes through the Tokara Strait where NS located, its axis varies greatly among years due to the large meander of Kuroshio (Yamashiro and Kawabe 2002). When the Kuroshio axis moving northward occasionally, the pelagic larvae of $P$. coelestis from Okinawa may have opportunities to reach NS and thus increase the genetic exchange between NS and SK.

In conclusion, the mitochondrial DNA sequence analyses provided a useful probe to detect the population structure of $P$. coelestis among different localities in Taiwan and Japan. The results demonstrated not only a link between phenotypic and genetic variations of $P$. coelestis populations but also the genetic divergence between mainland Japan and Okinawa-Taiwan groups. This study also showed the connectivity between local populations which can provide useful information on the design of future marine reserves in the northern West Pacific.
Acknowledgments We are grateful to the valuable comments of four reviewers. We would like to thank Ming-Jay Ho, Hengyi Hsieh and You-Rong Cheng for their assistance in filed works. This study was supported by a grant (NSC95-2611-M002-011) from the National Science Council, ROC to CFD.

\section{References}

Allen GR (1991) Damselfishes of the world. Mergus, Melle

Avise J (1998) Phylogeography. Harvard University Press, Cambridge Chen WY (1992) An ecological study on the reproduction of neon damselfish Pomacentrus coelestis on the northern coast of Taiwan. Master's Thesis, Institute of Fisheries Sciences, National Taiwan University, Taipei

Chen CA, Ablan MCA, MacManus JW, Cabanban A, Bell JD, Tuan VS, Cabanban AS, Shao KT (2004) Mitochondrial DNA analysis of the genetic structure among populations of Hardwicki wrass, Thallasoma hardwicki, in the northern South China Sea. Mar Biotechnol 6:312-326

Chiang TY, Schaal BA (2006) Phylogeography of plants in Taiwan and the Ryukyu Archipelago. Taxon 55:31-41

Clement M, Posada D, Crandall KA (2001) TCS: a computer program to estimate gene genealogies. Mol Ecol 9:1657-1660

CLIMAP Project Members (1981) Seasonal reconstructions of the Earth's surface at the Last Glacial Maximum. Geol Soc Am Map Chart Ser MC-36, 1-18

Conover DO, Clarke LM, Munch SB, Wagner GN (2006) Spatial and temporal scales of adaptive divergence in marine fishes and implications for conservation. J Fish Biol 69:21-47

Cowen RK, Paris CB, Srinivasan A (2006) Scaling of connectivity in marine populations. Science 311:522-527

Doherty PJ, Planes S, Mather P (1995) Gene flow and larval duration in seven species of fish from the Great Barrier Reef. Ecology 76:2373-2391

Domingues VS, Bucciarelli G, Almada VC, Bernardi G (2005) Historical colonization and demography of the Mediterranean damselfish, Chromis chromis. Mol Ecol 14:4051-4063

Excoffier L, Smouse PE, Quattro JM (1992) Analysis of molecular variance inferred from metric distances among DNA haplotypes: application of human mitochondrial DNA restriction data. Genetics 131:479-491

Fauvelot C, Bernardi G, Planes S (2003) Reductions in the mitochondrial DNA diversity of coral reef fish provide evidence of population bottlenecks resulting from Holocene sea-level change. Evolution 57:1571-1583

Fu Y-X (1996) New statistical tests for DNA samples from a population. Genetics 143:557-570

Fu Y-X, Li W-H (1993) Statistical tests of neutrality of mutation. Genetics 133:693-709

Gaggiotti OE, Excoffier L (2000) A simple method of removing the effect of a bottleneck and unequal population sizes on pairwise genetic distances. Proc R Soc B 267:81-87

Grant SW, Bowen BW (1998) Shallow population histories in deep evolutionary lineages of marine fishes: insight from sardines and anchovies and lessons for conservation. J Hered 89:415-426

Grether GF, Cummins ME, Hudon J (2005) Countergradient variation in the sexual coloration of guppies (Poecillia reticulata) drosopterin synthesis balances carotenoid availability. Evolution 59:175-188

Hellberg ME (1996) Dependence of gene flow on geographic distance in two solitary corals with different larval dispersal capabilities. Evolution 50:1167-1175

Jones GP, Milicich MJ, Emslie MJ, Lunow C (1999) Self-recruitment in a coral reef fish population. Nature 402:802-804 
Jones GP, Planes S, Thorrold SR (2005) Coral reef fish larvae settle close to home. Curr Biol 15:1314-1318

Kojima S, Kamimura S, Iijima A, Kimura T, Kurozumi T, Furota T (2006) Molecular phylogeny and population structure of tideland snails in the genus Cerithidea around Japan. Mar Biol 149:525535

Kokita T (2003) Potential latitudinal variation in egg size and number of a geographically widespread reef fish, revealed by commonenvironment experiments. Mar Biol 143:593-601

Kokita T (2004) Latitudinal compensation in female reproductive rate of a geographically widespread reef fish. Environ Biol Fish 71:213-224

Kumar S, Tamura K, Nei M (2004) MEGA3: integrated software for molecular evolutionary genetics analysis and sequence alignment. Brief Bioinform 5:150-163

Lee WJ, Conroy J, Howell WH, Kocher TD (1995) Structure and evolution of teleost mitochondrial control regions. J Mol Evol 41:5466

Liang WD, Tang TY, Yang YJ, Ko MT, Chuang WS (2003) Upperocean currents around Taiwan. Deep Sea Res II:1085-1105

Liu SV, Dai CF, Fan TY, Yu HT (2005) Cloning and characterization of microsatellite loci in a gorgonian coral, Junceella juncea (Anthozoa; Octocorallia; Ellisellidae) and its application in clonal genotyping. Mar Biotechnol 7:26-33

Marcil J, Swain DP, Hutchings JA (2006) Countergradient variation in body shape between two populations of Atlantic cod (Gadus morhua). Proc R Soc B 273:217-223

Messmer V, van Herwerden L, Munday PL, Geoffrey PJ (2005) Phylogeography of colour polymorphism in the coral reef fish Pseudochromis fuscus from Papua New Guinea and the Great Barrier Reef. Coral Reefs 24:392-402

Meyer A (1994) Molecular phylogenetic studies of fish. In: Beaumont AR (ed) Genetics and evolution of aquatic organisms. Chapman \& Hall, London, pp 219-249

Mousseau TA, Fox CW (1998) The adaptive significance of maternal effects. Trends Ecol Evol 13:403-407

Mukai T, Suzuki T, Nishida M (2004) Genetic and geographical differentiation of Pandaka gobies in Japan. Ichthyol Res 51:222-227

Mukai T, Suzuki T, Nishida M (2005) Mitochondrial DNA divergence in yoshinobori gobies (Rhinogobius species complex) between the Bonin Islands and the Japan-Ryukyu Archipelago. Ichthyol Res 52:410-413

Nei M (1978) Estimation of average heterozygosity and genetic distance from a small number of individuals. Genetics 89:583-590

Nei M (1987) Molecular evolutionary genetics. Columbia University Press, New York

Nelson JS, Hoddell RJ, Chou LM, Chan WK, Phang VPE (2000) Phylogeographic structure of false clownfish, Amphiprion ocellaris, explained by sea level changes on the Sunda Shelf. Mar Biol 137:727-736

Ogoh K, Ohmiya Y (2005) Biogeography of luminous marine ostracod driven irreversibly by the Japan Current. Mol Biol Evol 22:15431545

Ota H (1998) Geographical patterns of endemism and speciation in amphibians and reptiles of the Ryukyu Archipelago, Japan, with special reference to their paleogeographical implications. Res Popul Ecol 40:189-204

Palumbi SR (1996) What can molecular genetics contribute to marine biogeography? An urchin's tale. J Exp Mar Biol Ecol 203:75-92
Palumbi SR (2003) Population genetics, demographic connectivity, and the design of marine reserves. Ecol Appl 13:S146-S158

Planes S (2002) Biogeography and larval dispersal inferred from population genetic analysis. In: Sale PF (ed) Coral reef fishes: dynamics and diversity in a complex ecosystem. Academic Press, New York, pp 201-220

Rogers AR, Hapending H (1992) Population growth makes waves in the distribution of pairwise genetic differences. Mol Biol Evol 9:552-569

Salvanes AGV, Skjaeraasen JE, Nilsen T (2004) Subpopulations of coastal cod with different behavior and life-history strategies. Mar Ecol Prog Ser 267:241-251

Schneider S, Roessli D, Excoffier L (2000) Arlequin version 2.0: a software for population genetics data analysis. Genetics and Biometry Laboratory, University of Geneva, Switzerland

Shaklee JM (1984) Genetic variation and population structure in the damselfish, Stegastes fasciolatus, throughout the Hawaiian Archipelago. Copeia 1984:629-640

Shulman MJ, Bermingham E (1995) Early life histories, ocean currents, and population genetics of Caribbean reef fishes. Evolution 49:897-910

Slatkin M, Hudson RR (1991) Pairwise comparisons of mitochondrial DNA sequences in stable and exponentially growing populations. Genetics 129:555-562

Suzuki K, Hioki S, Kashihara M (1985) Life history of the damselfish Pomacentrus coelestis in Suruga Bay, Japan. J Fac Mar Sci Technol Tokai Univ 21:99-114

Swearer SE, Caselle JE, Lea DW, Warner R (1999) Larval retention and recruitment in an island population of a coral-reef fish. Nature 402:799-802

Tanaka Y, Nitta M (1997) Reproduction and rearing of damselfish, Pomacentrus coelestis, in the aquarium. Bull Inst Oceanic Res Develop Tokai Univ 18:51-62

Taylor MS, Hellberg ME (2003) Genetic evidence for local retention of pelagic larvae in a Caribbean reef fish. Science 299:107-109

Taylor MS, Hellberg ME (2005) Marine radiations at small geographic scales: speciation in neotropical reef gobies (Elacatinus). Evolution 59:374-385

Templeton AR, Routman E, Phillips CA (1995) Separating population structure from population history: a cladistic analysis of the geographical distribution of mitochondrial DNA haplotypes in the tiger salamander, Ambystoma tigrinum. Genetics 140:767-782

Thompson JD, Higgins DG, Gibson TJ (1994) CLUSTAL W: improving the sensitivity of progressive multiple sequence alignment through sequence weighting, position-specific gap penalties and weight matrix choice. Nucleic Acids Res 22:4673-4680

Tseng MC, Tzeng WN, Lee SC (2006) Population genetic structure of the Japanese eel Anguilla japonica in the northwest Pacific Ocean: evidence of non-panmictic populations. Mar Ecol Prog Ser 308:221-230

Ujiié H, Tanaka Y, Ono T (1991) Late quaternary paleoceanographic record from the middle Ryukyu Trench slope, northwest Pacific. Mar Micropaleontol 18:115-128

Wright HA, Wooton RJ, Barber I (2004) Interpopulation variation in early growth of threespine stickleback (Gasteroteus aculeatus) under laboratory conditions. Can J Fish Aquat Sci 61:1832-1838

Yamashiro T, Kawabe M (2002) Variations of Kuroshio axis south of Kyushu in relation to the large meander of Kuroshio. J Oceannogr 58:487-503 